\title{
Ineficacia de la acción de repetición en el municipio de Florencia, Caquetá. Estudio de caso, 2010-2016
}

Ineffectiveness of the action of repetition in the municipality of Florencia, Caquetá. Case study, 2010-2016

Ineficácia da ação de repetição no município de Florencia, Caquetá, Colômbia. Estudo de caso, 2010-2016

\section{Juan Sebastián Bustos Ortega ${ }^{1}$ Carlos Javier Rosas Sánchez ${ }^{2}$}

Recibido: 5 de agosto de 2019 Aprobado: 16 de septiembre de 2019 Publicado: 5 de noviembre de 2019

Cómo citar este artículo: Juan Sebastián Bustos Ortega y Carlos Javier Rosas Sánchez. Ineficacia de la acción de repetición en el municipio de Florencia, Caquetá, estudio de caso 2010-2016.

DIXI 30, julio-diciembre 2019, 1-19.

DOI: https://doi.org/10.16925/2357-5891.2019.02.07

Artículo de investigación. https://doi.org/10.16925/2357-5891.2019.02.07

1 Especialista en Derecho Contencioso Administrativo de la Universidad de la Amazonia. Abogado de la Universidad de la Amazonia. Abogado litigante.

Correo electrónico: jsboabogado@hotmail.com

2 Especialista en Derecho Contencioso Administrativo de la Universidad de la Amazonia. Abogado Universidad de la Amazonia. Abogado litigante. 


\section{Resumen}

Propósito: el propósito del presente escrito es establecer la eficacia de la acción de repetición y con ello determinar el impacto del medio de control en la recuperación dineraria invertida para el pago de sentencias judiciales en el municipio de Florencia, Caquetá, en el periodo 2010-2016.

Metodología: para lograr este objetivo, se planteó una investigación básica, con un tipo de estudio descriptivo, bajo el método de investigación deductivo, consultando fuentes estadísticas y valiéndose de la sistematización de datos para su análisis como técnica de recolección de información.

Hallazgos: la responsabilidad civil extracontractual es una de las garantías propias de los Estados modernos, con la cual se busca dotar a la sociedad de mecanismos para ejercer el pago de indemnizaciones con ocasión a la conducta de los funcionarios públicos; por tanto, se han implementado en nuestra normatividad acciones o medios de control como mecanismos procesales habilitantes para solicitar el resarcimiento del perjuicio.

Conclusiones: en el municipio de Florencia, Caquetá, la eficacia de la acción de repetición en las vigencias 2010-2016 es nula, la Alcaldía tan solo ha iniciado tres acciones de las cuales una se archivó, frente a un total de 89 condenas en contra del municipio.

Palabras clave: acción de repetición, Alcaldía de Florencia, Caquetá, responsabilidad civil extracontractual, sentencias judiciales.

\section{Abstract}

Purpose: The purpose of this paper is to establish the effectiveness of the action of repetition, and thus to determine the impact of the means of control on the recovery of money invested for the payment of judicial sentences in the municipality of Florencia, Caquetá, in the period 2010-2016.

Methodology: In order to achieve this objective, a basic research was proposed, with a descriptive study and a deductive research method. It will consult statistical sources and use the systematization of data for its analysis as an information collection technique.

Findings: Extra-contractual civil liability is one of the guarantees inherent to modern states, with which it is sought to provide society with mechanisms to exercise the payment of compensation on the conduct of public officials. Therefore, actions or means of control were implemented in our regulations as procedural mechanis$\mathrm{ms}$ to request compensation for damages.

Conclusions: in the municipality of Florencia, Caquetá, the effectiveness of the action of repetition in the 20102016 period is null. The City Hall has only initiated three actions of which only one was filed of 89 convictions against the municipality.

Keywords: Action of repetition, Florencia's City Hall, Caquetá, extra-contractual civil liability, judicial sentences.

\section{Resumo}

Propósito: o objetivo deste texto é estabelecer a eficácia da ação de repetição e, com isso, determinar o impacto do meio de controle na recuperação financeira investida na recuperação para o pagamento de sentenças judiciais no município Florencia, Caquetá, entre 2010 e 2016.

Metodologia: para atingir esse objetivo, apresenta-se uma pesquisa básica, com um tipo de estudo descritivo, sob o método de pesquisa dedutiva, que consulta fontes estatísticas e se vale da sistematização de dados para sua análise como técnica de coleta de informação.

Achados: a responsabilidade civil extracontratual é uma das garantias próprias dos Estados modernos, com a qual se busca dotar a sociedade de mecanismos para exercer o pagamento de indenizações devido à conduta 
dos funcionários públicos; portanto, têm sido implantadas, em nossa legislação, ações ou meios de controle como mecanismos processuais habilitantes para solicitar o ressarcimento do prejuízo.

Conclusões: no município de Florencia, Caquetá, a eficácia da ação de repetição nas vigências 2010-2016 é nula. A prefeitura somente iniciou três ações, das quais uma foi arquivada, diante de um total de 89 condenações contra o município.

Palavras chave: ação de repetição, prefeito de Florença, Caquetá, responsabilidade civil, decisões judiciais.

\section{INTRODUCCIÓN}

Una de las grandes tareas del derecho contencioso administrativo en Colombia es dar solución a conflictos jurídicos de corte preparatorio, a través de la acción de reparación directa y nulidad y restablecimiento del derecho. Esta tarea judicial causa cada año un gran número de condenas contra la administración y con ella, la fuga de capitales del Estado hacia cuentas particulares, derivado de una condena en la que el Estado ha sido encontrado responsable. Por tal motivo, el constituyente contempló la acción de repetición como un mecanismo al alcance de la Administración Pública, del cual debe echar mano a la hora de llamar a sus agentes de quienes se derivó la conducta dolosa o gravemente culposa generadora de daños antijurídicos y causante de la condena al Estado.

Ahora bien, siendo que las condenas contra el Estado, y en particular contra la Alcaldía Municipal, son muchas, y que el capital de las mismas es significativo, en este trabajo se cuestiona la eficacia de la acción de repetición en la Alcaldía Municipal de Florencia, Caquetá. Con ello, se pretende determinar la eficacia del instrumento a través de un análisis principalmente estadístico.

Para lograr este objetivo, se planteó un tipo de investigación básica, con un estudio descriptivo, bajo el método de investigación deductivo, consultando fuentes estadísticas y valiéndose de la sistematización de datos para su análisis como técnica de recolección de información. Con ello, se espera acceder a una serie de conocimientos específicos, cuántas sentencias condenatorias se han proferido contra la Administración Municipal y el monto de las condenas, el número de acciones de repetición iniciadas por la Administración y en su defecto por el Ministerio Público; con lo cual se establecerá un juicio de valor que permita determinar la eficacia del mecanismo procesal en la Alcaldía Municipal de Florencia, Caquetá, entre los años 2010-2017. 


\section{CARACTERÍSTICAS EL MEDIO DE CONTROL DE REPETICIÓN}

\section{Origen y evolución}

El origen de la responsabilidad del Estado, de la cual se deriva la acción de repetición, tiene su primer escenario en la Antigua Grecia, donde se concebía la irresponsabilidad del Estado. En ese sentido, el Estado no era responsable de los daños que pudiere causar a los ciudadanos ni sus bienes, más que ante las autoridades divinas; así sucedió en las legislaciones de Esparta y Atenas?

En la época de la Revolución Francesa en 1789, se pensó en imponer a los gobernantes algunas limitantes que condujeran a dar cuenta a los gobernados, haciéndolos responsables por sus actos frente a los administrados. Fue así como el artículo 15 de la Declaración de los Derechos del Hombre y del Ciudadano consagró: "La sociedad tiene el derecho de pedirle cuentas de su administración a todo agente público"2.

Según Mestre y Garcés $^{3}$, la evolución de la acción de repetición en las teorías de la responsabilidad del Estado pasa por los estadíos del surgimiento del Estado liberal, en el cual "se consideró que el Estado no era responsable por los daños que ocasionara con ocasión a su actividad, debido a que este y sus agentes eran meros ejecutores de la soberanía popular". Con ello, el Estado quedaba excluido de la responsabilidad por daños, pero sus agentes sí estaban vinculados a la responsabilidad por los daños que cometieran en ejercicio de sus funciones:

Al terminar la Primera Guerra Mundial, surgieron teorías de doctrinantes que buscaban la indemnización por los hechos $u$ omisiones cometidos por los funcionarios públicos que le habían causado lesión o daño a los particulares, con el fin de reclamar así la responsabilidad patrimonial en favor de las víctimas.

Posteriormente, por vía jurisprudencial, se dio comienzo al desarrollo del principio de la responsabilidad patrimonial del Estado. El Tribunal

1 Véase Álvaro Bustamante Ledesma. LA RESPONSABILIDAD EXTRACONTRACTUAL DEL ESTADO. Leyer. (2003). Pág. 5.

2 Véase Olga Amparo Barrientos Yépez. LETRAs JURídicas volumEN 5. Editorial EEPP. (2000).

3 Véase Ida María Mestre Ordóñez y María Catalina Garcés Restrepo. LA ACción DE REPETICIÓN Y EL LLAMAMIENTO EN GARANTíA LEY 678 DE 2001. Editorial Universidad Javeriana. (2004). 
de Conflictos francés, con su célebre Fallo Blanco de 1873, recogió la legislación de los países occidentales, consagrando la responsabilidad del Estado independientemente de que estuviera consagrada en el sistema normativo, y de que su actividad fuera de gestión o de poder. Este fallo marcó una tendencia hacia una mayor responsabilidad del Estado, creciendo también la posibilidad de una acumulación de responsabilidad entre el funcionario y la administración, para garantizar que fuera reparado el daño causado al particular. ${ }^{4}$

En 1951 con el Fallo Laurelle ${ }^{5}$, el funcionario del Estado se hace responsable por los perjuicios que cause por sus faltas o culpas personales a la Administración, cometidas por fuera del ejercicio de sus funciones o con ocasión a ellas. En el sistema anglosajón, el agente estatal que generara el daño debía responder con su patrimonio, es decir que era muy importante, en el momento de obtener un cargo, la solvencia económica de quien quería aplicar para el mismo.

\section{En Colombia}

De acuerdo con la evolución de nuestro sistema legislativo, en un comienzo los gobernantes gozaron de una época de irresponsabilidad absoluta, en la que sus actuaciones no eran discutibles. Sin embargo, el tema de la responsabilidad estatal fue evolucionando, de tal manera que la responsabilidad de los funcionarios del Estado se empezó a discutir. Fue en ese momento cuando las entidades públicas comenzaron a asumir su responsabilidad en las actuaciones de gestión y prestación de servicios públicos.

En este Estado inicial, la legislación en materia administrativa no desarrollaba conceptos fundamentales de la responsabilidad, como lo son el dolo o la culpa grave. Eran aplicables, entonces, las definiciones contenidas en los artículos 63 y 2341 del Código Civil.

4 Id.

5 Véase Libardo Rodríguez. DERECho administrativo. Temis. (2000). Pág. 416. 
Tabla de análisis documental ${ }^{6}$

\begin{tabular}{|c|c|c|}
\hline Norma & Contenido & Concepto \\
\hline & \multirow{2}{*}{$\begin{array}{l}\text { "Los particulares no son responsables ante las } \\
\text { autoridades sino por infracción de la Constitu- } \\
\text { ción y de las Leyes. Los funcionarios públicos lo } \\
\text { son por la misma causa y por extralimitación de } \\
\text { funciones o por omisión en el ejercicio de estas". }\end{array}$} & \multirow{2}{*}{$\begin{array}{l}\text { Aunque no da pie a la res- } \\
\text { ponsabilidad del Estado, abre } \\
\text { camino en el derecho colom- } \\
\text { biano al establecimiento de la } \\
\text { responsabilidad individual de } \\
\text { los servidores públicos. }\end{array}$} \\
\hline Artículo 20 & & \\
\hline Ley 3 de 1986 & $\begin{array}{l}\text { "Artículo 14. Los departamentos repetirán contra } \\
\text { las personas que hubieren efectuado eleccio- } \\
\text { nes, nombramientos o remociones ilegales de } \\
\text { funcionarios, el valor de las indemnizaciones } \\
\text { que hubieren pagado por esta causa. Las } \\
\text { violaciones de la Ley, para estos efectos, deben } \\
\text { haber sido manifiestas y ostensibles conforme a } \\
\text { la respectiva decisión de la autoridad judicial". }\end{array}$ & $\begin{array}{l}\text { Permite a los departamentos } \\
\text { repetir contra el nominador } \\
\text { que ha incurrido en una irregu- } \\
\text { laridad de la cual se derive el } \\
\text { pago de una indemnización. }\end{array}$ \\
\hline Ley 11 de 1986 & $\begin{array}{l}\text { "Los municipios repetirán contra las personas } \\
\text { que hubieren efectuado elecciones, nombra- } \\
\text { mientos o remociones ilegales de funcionarios, } \\
\text { el valor de las indemnizaciones que hubieren } \\
\text { pagado por esta causa. Las violaciones de la } \\
\text { Ley, para estos efectos, deben haber sido ma- } \\
\text { nifiestas u ostensibles conforme a la respectiva } \\
\text { decisión de la autoridad judicial". }\end{array}$ & $\begin{array}{l}\text { Abre la posibilidad para repetir } \\
\text { contra el nominador que ha } \\
\text { realizado una elección ilegal a } \\
\text { nivel de los municipios. }\end{array}$ \\
\hline $\begin{array}{l}\text { Jurisprudencia. Corte } \\
\text { Suprema de Justicia. Sala } \\
\text { de Negocios Generales. Bo- } \\
\text { gotá, octubre } 31 \text { de 1950, } \\
\text { M.P. Rodríguez Peña G.J., } \\
\text { Tomo LXVIII, N. . S2087-288, } \\
\text { P-493. }\end{array}$ & $\begin{array}{l}\text { "Esta conclusión no se modifica, porque -como } \\
\text { aquí sucede-con la culpa del servicio concurre } \\
\text { una falta personal del agente, cual era la de } \\
\text { conducir su vehículo en estado de embriaguez; } \\
\text { demuestra apenas que en razón de aquella } \\
\text { concurrencia de culpabilidad, los dos - agente } \\
\text { y administración- son responsables solidaria- } \\
\text { mente, ante el perjudicado, cada uno por su } \\
\text { propia culpa, y que la segunda goza de derecho } \\
\text { de repetir contra el primero por el valor de la } \\
\text { correspondiente indemnización”. }\end{array}$ & $\begin{array}{l}\text { Da inicio a la teoría de } \\
\text { responsabilidad solidaria de } \\
\text { funcionario y administración, } \\
\text { permitiendo a la adminis- } \\
\text { tración repetir contra el } \\
\text { funcionario. }\end{array}$ \\
\hline Decreto 222 de 1983 & \multirow[b]{2}{*}{$\begin{array}{l}\text { "Sin perjuicio de las sanciones penales a que } \\
\text { hubiere lugar, los empleados oficiales responde- } \\
\text { rán civilmente por los perjuicios que causen a } \\
\text { las entidades a que se refiere este estatuto, a } \\
\text { los contratistas o a terceros, cuando celebren } \\
\text { contratos sin el cumplimiento de los requisitos } \\
\text { y formalidades consignadas en el presente } \\
\text { estatuto. Esta responsabilidad cobija también a } \\
\text { las personas que hubieren cesado en el ejercicio } \\
\text { de sus cargos, siempre que ella deduzca por } \\
\text { hechos u omisiones ocurridos en el desempeño } \\
\text { de los mismos". }\end{array}$} & \multirow{2}{*}{$\begin{array}{l}\text { Hay apertura a la responsabi- } \\
\text { lidad civil del funcionario ante } \\
\text { la entidad afectada con su } \\
\text { actuación, por actos contrac- } \\
\text { tuales ilegales. }\end{array}$} \\
\hline Artículo 290 & & \\
\hline $\begin{array}{l}\text { Código Contencioso Admi- } \\
\text { nistrativo }\end{array}$ & $\begin{array}{l}\text { "La sentencia solo imponía la condena en } \\
\text { contra de la entidad pública, sin perjuicio, de } \\
\text { su derecho a obtener el reembolso de lo que le } \\
\text { correspondiere al agente y a la posibilidad en } \\
\text { cabeza de la víctima de demandar a la entidad, } \\
\text { al funcionario o a ambos, en el evento de que } \\
\text { aquel debiera responder en todo o en parte". }\end{array}$ & $\begin{array}{l}\text { Cambia el paradigma de } \\
\text { responsabilidad principal en } \\
\text { cabeza del funcionario para } \\
\text { pasar a la responsabilidad } \\
\text { del Estado y la solidaridad del } \\
\text { funcionario, sin perjuicio de la } \\
\text { posibilidad de repetir contra } \\
\text { el funcionario, buscando el } \\
\text { reintegro del capital pagado. }\end{array}$ \\
\hline
\end{tabular}

(continúa)

6 Ida María Mestre Ordóñez y María Catalina Garcés Restrepo, supra, nota 3. 
(viene)

\begin{tabular}{|c|c|c|}
\hline Norma & Contenido & Concepto \\
\hline Ley 80 de 1993 & \multirow{2}{*}{$\begin{array}{l}\text { "Sin perjuicio del llamamiento en garantía, } \\
\text { repetirán contra los servidores públicos, } \\
\text { contra el contratista o los terceros respon- } \\
\text { sables, según el caso, por las indemniza- } \\
\text { ciones que deban pagar como consecuen- } \\
\text { cia de la actividad contractual". }\end{array}$} & \multirow{2}{*}{$\begin{array}{l}\text { Cuando de la actividad contractual } \\
\text { llevada a cabo por un funcionario } \\
\text { se derive la condena contra la enti- } \\
\text { dad, a título de dolo o culpa grave, } \\
\text { la entidad podrá repetir contra el } \\
\text { funcionario. }\end{array}$} \\
\hline Artículo 4 \#7 & & \\
\hline Ley 270 de 1996 & \multirow[b]{2}{*}{$\begin{array}{l}\text { "La responsabilidad de los funcionarios y } \\
\text { empleados judiciales por cuya conduc- } \\
\text { ta dolosa o gravemente culposa haya } \\
\text { sido condenado el Estado, será exigida } \\
\text { mediante la acción civil de repetición de la } \\
\text { que este es titular, excepto el ejercicio de } \\
\text { la acción civil respecto de conductas que } \\
\text { puedan configurar hechos punibles". }\end{array}$} & \multirow{2}{*}{$\begin{array}{l}\text { Establece la acción de repetición a } \\
\text { los funcionarios de la administra- } \\
\text { ción de justicia. }\end{array}$} \\
\hline Artículo 72 & & \\
\hline Ley 288 de 1996 & \multirow{2}{*}{$\begin{array}{l}\text { "Las indemnizaciones que se paguen o } \\
\text { efectúen de acuerdo con lo previsto en } \\
\text { esta ley, darán lugar al ejercicio de la } \\
\text { acción de repetición de que trata el inciso } \\
\text { segundo del artículo } 90 \text { de la Constitución } \\
\text { Política". }\end{array}$} & \multirow{2}{*}{$\begin{array}{l}\text { Se trata de la acción y repetición } \\
\text { derivada de las condenas contra la } \\
\text { administración por violaciones a } \\
\text { derechos humanos. }\end{array}$} \\
\hline Artículo 12 & & \\
\hline Ley 446 de 1998 & \multirow[b]{2}{*}{$\begin{array}{l}\text { "Las entidades públicas deberán promover } \\
\text { la misma acción [de reparación directa] } \\
\text { cuando resulten condenadas o hubieren } \\
\text { conciliado por una actuación administra- } \\
\text { tiva originada en culpa grave o dolo de } \\
\text { un servidor o exservidor público que no } \\
\text { estuvo vinculado al proceso respectivo, o } \\
\text { cuando resulten perjudicadas por la ac- } \\
\text { tuación de un particular o de otra entidad } \\
\text { pública". }\end{array}$} & \multirow[b]{2}{*}{$\begin{array}{l}\text { Esta norma precisó el momento } \\
\text { a partir del cual se puede ejercer } \\
\text { la acción, estableciendo que la } \\
\text { caducidad se contaría desde el día } \\
\text { siguiente a aquel en que se efectuó } \\
\text { el pago total, es decir, que si el } \\
\text { pago se presenta de forma diferida, } \\
\text { a partir de la cancelación de la } \\
\text { última cuota. }\end{array}$} \\
\hline Artículo 86 & & \\
\hline
\end{tabular}

Fuente: Elaboración propia

\section{EN LA CONSTITUCIÓN DEL 91}

La consagración constitucional del año 1991 fue lo que realmente le dio la significación y trascendencia al tema de la responsabilidad personal de los servidores públicos. La nueva Carta Política, al lado de la responsabilidad del Estado, establece la obligación de este de reparar los daños antijurídicos causados a los administrados, consagrando igualmente la obligación de repetir en contra de sus agentes, cuando con su conducta dolosa o gravemente culposa dan lugar a que se declare la responsabilidad de aquel? .

7 Ida María Mestre Ordóñez y María Catalina Garcés Restrepo, supra, nota 3. Pág. 31. 


\section{Ley 1437}

La Ley 1437 de 2011 CPACA, actual Código de Procedimiento Administrativo y Contencioso Administrativo, estableció un artículo que expresamente dentro del título III "Medios de Control" hace referencia a una acción Ilamada de repetición:

ARTíCULO 142 C.C.A REPETICIÓN: Cuando el Estado haya debido hacer un reconocimiento indemnizatorio con ocasión de una condena, conciliación u otra forma de terminación de conflictos que sean consecuencia de la conducta dolosa o gravemente culposa del servidor o ex servidor público o del particular en ejercicio de funciones públicas, la entidad respectiva deberá repetir contra estos por lo pagado.

La pretensión de repetición también podrá intentarse mediante el llamamiento en garantía del servidor o ex servidor público o del particular en ejercicio de funciones públicas, dentro del proceso de responsabilidad contra la entidad pública.

Cuando se ejerza la pretensión autónoma de repetición, el certificado del pagador, tesorero o servidor público que cumpla tales funciones en el cual conste que la entidad realizó el pago será prueba suficiente para iniciar el proceso con pretensión de repetición contra el funcionario responsable del daño. ${ }^{8}$

\section{Concepto}

El diccionario define el verbo repetir como "reclamar contra tercero, a consecuencia de evicción, pago o quebranto que padeció el reclamante" ${ }^{\prime 9}$. Esta definición se adapta al concepto jurídico envuelto dentro de la institución de la acción de repetición, ya que lo que esta busca es el resarcimiento del detrimento patrimonial sufrido por el Estado, a causa de una actuación dolosa o gravemente culposa de uno de sus agentes. Es una acción contenciosa aportada por la Constitución Política de 1991 al consagrar en el artículo 90 superior: "En el evento de ser condenado el Estado a la reparación patrimonial de uno de tales daños, que hayan sido consecuencia de la conducta dolosa o gravemente culposa de un agente suyo, aquel deberá repetir contra este".

8 Congreso de la República. Ley 1437 de 2011. Por la cual se expide el Código de Procedimiento Admistrativo y de lo Contencioso Administrativo. Enero 18 de 2011.

9 Véase Real Academia Española. DICcIONARIO DE LA LENGUA ESPAÑOLA. 23. a edición. RAE. (2014). 
La finalidad de esta acción es el interés público, pues se busca proteger el patrimonio del Estado, necesario para alcanzar la realización efectiva de los fines y propósitos del Estado social y democrático de derecho. Esta acción propende a la obtención de un reembolso por parte de los agentes que, con su conducta dolosa o gravemente culposa, en el desempeño de sus funciones han causado un daño y con este, el reconocimiento indemnizatorio a la víctima por parte del Estado, concretado por una condena judicial, una conciliación o cualquier otro mecanismo alternativo de solución de conflictos. Además del fin resarcitorio inmerso, la acción de repetición también puede considerarse como una "herramienta para conseguir la moralidad y eficiencia de la función pública y generar un efecto preventivo sobre el actuar de los servidores públicos"10.

Sin embargo, hay quienes consideran que la acción de repetición es netamente de carácter patrimonial y no moralista ni retributivo; por lo cual, no se ve claro, según esta tendencia, por qué se evocan los principios de moralidad y eficiencia ${ }^{11}$.

\section{ASPECTOS PROCESALES}

1. Conductas: dan lugar al ejercicio de la acción; ejercer la acción de repetición es deber de las entidades públicas cuando deban indemnizar a un particular por una conducta realizada con dolo o culpa grave del funcionario, exfuncionario o particular en ejercicio de funciones públicas, quien deberá retribuir este valor. Constituye una falta disciplinaria para quien debiendo ejercitar la acción, omitió hacerlo. Existen eventos en los cuales a pesar de que tenga el Estado que indemnizar, el funcionario o exfuncionario ha actuado en cumplimiento de sus deberes, con la diligencia y cuidado debido, pero no obstante se ha causado daño.

En estos eventos, la entidad no debe iniciar acción de repetición contra el servidor. El dolo y la culpa grave son aspectos subjetivos de la conducta cuya valoración debe hacer el juez con el propósito de limitar las condenas, porque no toda culpa es fundamento de responsabilidad patrimonial. Sin embargo, la Ley 678 de 2001 definió cuándo una conducta es dolosa o gravemente culposa, y hace la descripción de algunas conductas de las cuales se presume que el agente actuó de una u otra manera. El Consejo de Estado, a este respecto, no se ha pronunciado uniformemente; en algunas ocasiones, se ha remitido al artículo 63 del Código Civil y en otras, a los artículos 6

10 Véase Presidencia de la República de Colombia. CARTILLA INSTRUCTIVA DE ACCIÓN DE REPETICión Y LLAmamiento en Garantía. Presidencia de la República. (2004).

11 Véase Édgar Arturo León Benavides. ACCIÓN DE REPETICIÓN: LEY 678 DE 2001. Librería Profesional. (2003). 
y 91 de la Constitución Política, que establecen que también serán responsables los servidores públicos por extralimitación u omisión en el ejercicio de sus funciones, sin poder eximirse de esta responsabilidad por el cumplimiento de un mandato superior. Al consagrar tanto la Constitución como la Ley 678 que la acción de repetición debe interponerse cuando se causa un daño por conducta dolosa o gravemente culposa, se pretende excluir la procedencia de la misma en el evento de que se cause por culpa leve o levísima del agente.

Con el ánimo de facilitar la prueba de la culpa grave y del dolo, los artículos 5 y 6 de la norma hablan de presunciones legales y enumeran una serie de conductas donde debe entenderse que han sido realizadas de manera dolosa o gravemente culposa.

\section{De los sujetos procesales:}

Activo:

a) La entidad afectada.

b) El Ministerio Público.

c) El Ministerio de Justicia y del Derecho, a través de la Dirección de Defensa Judicial de la Nación, cuando la perjudicada con el pago sea una entidad pública del orden nacional (que no es el caso particular). ${ }^{12}$

Pasivo:

Son destinatarios de la acción los servidores públicos, ex servidores públicos y los particulares que ejercen temporalmente funciones públicas, que hayan causado la condena al Estado por la acción u omisión de sus funciones, produciendo un daño antijurídico. Los particulares que ejercen funciones públicas son Ilamados "auxiliares de la administración" cuya vinculación es temporal, tales como: contratistas, interventores, consultores y asesores que participan en la celebración, ejecución y liquidación de contratos con el Estado. El artículo 52 de la Ley 80 de 1993 señala la responsabilidad del contratista en estos términos: "Los contratistas responderán civil y penalmente por sus acciones y omisiones en la actuación contractual en los términos de la ley".

De lo anterior, se deduce que para los contratistas se genera responsabilidad por la contravención a las disposiciones sustantivas; la responsabilidad penal que se vincula al dolo o culpa grave y la responsabilidad civil que trata de la reparación del daño a la víctima. El artículo 1604 del Código Civil se refiere sobre

12 Congreso de la República. Ley 678 de 2000. Por medio de la cual se reglamenta la determinación de responsabilidad patrimonial de los agentes del Estado a través del ejercicio de la acción de repetición o de llamamiento en garantía con fines de repetición. Agosto 3 de 2000 . 
el particular, estipulando que en los contratos que por su naturaleza son útiles al acreedor, el deudor solo es responsable de la culpa alta y de la leve cuando los contratos se hacen para beneficio recíproco de las partes, y de la levísima en los contratos en que el deudor es el único que se beneficia.

La misma norma, en su inciso final, establece que su reglamento haya de entenderse "sin perjuicio de las disposiciones especiales de las leyes o de las estipulaciones expresas de las partes". De acuerdo con esto, deben respetarse las exenciones derivadas de los pactos celebrados entre los contratantes, relativos a la cobertura de determinados niveles del elemento subjetivo de la culpa, pero teniendo en cuenta que nunca pondrá pactarse una cláusula de exoneración de la culpa grave o dolo, porque esta sería nula, ya que no se puede condonar el dolo futuro y de alguna manera la derogatoria del régimen de responsabilidad que es de orden público. La Ley 678 de 2001 en el parágrafo 2 del artículo 5 preceptúa que la acción de repetición también se puede ejercer contra funcionarios de la Rama Judicial y de la Justicia Penal Militar, así como en el evento de que el Estado pague las indemnizaciones previstas en la Ley 288 de $1996 .{ }^{13}$

3. Competencia: el nuevo Código Contencioso Administrativo, Ley 1437 de 2011, le otorga competencia a los diferentes órganos que conforman la jurisdicción de lo contencioso administrativo en la acción de repetición dependiendo del tipo de funcionario contra quien se emprenda y la cuantía indemnizada, así:

ARTíCULO 149 Inc. 13 CPACA. COMPETENCIA DEL CONSEJO DE ESTADO EN ÚNICA INSTANCIA: De la repetición que el Estado ejerza contra el Presidente de la República o quien haga sus veces, Senadores y Representantes, Ministros del Despacho, Directores de Departamento Administrativo, Procurador General de la Nación, Contralor General de la República, Fiscal General de la Nación, Magistrados de la Corte Suprema de Justicia, de la Corte Constitucional, del Consejo Superior de la Judicatura, Registrador Nacional del Estado Civil, Auditor General de la República, magistrados de los tribunales superiores de distrito judicial, de los tribunales administrativos y del Tribunal Superior Militar y, en general, de los representantes legales de los órganos y entidades del orden nacional. PARÁGRAFO 2. De las acciones de repetición que el Estado ejerza contra los Magistrados del Consejo de Estado, conocerá la Corte Suprema de Justicia en Sala Plena.

\footnotetext{
13 Ida María Mestre Ordóñez y María Catalina Garcés Restrepo, supra, nota 3.
} 
ARTÍCULO 152 InC 11 CPACA: COMPETENCIA DE LOS TRIBUNALES ADMINISTRATIVOS EN PRIMERA INSTANCIA: De la repetición que el Estado ejerza contra los servidores o ex servidores públicos y personas privadas que cumplan funciones públicas, incluidos los agentes judiciales, cuando la cuantía exceda de quinientos (500) salarios mínimos legales mensuales vigentes y cuya competencia no estuviere asignada al Consejo de Estado en única instancia.

ARTíCULO 154 Inc. 8: COMPETENCIA DE LOS JUECES ADMINISTRATIVOS EN ÚNICA INSTANCIA: De las acciones de repetición que el Estado ejerza contra los servidores o ex servidores públicos y personas privadas que cumplan funciones públicas, incluidos los agentes judiciales, cuando la cuantía no exceda de quinientos (500) salarios mínimos legales mensuales vigentes y cuya competencia no estuviere asignada al Consejo de Estado en única instancia. ${ }^{14}$

En materia de competencia territorial, la precitada Ley 678 de 2001 consagra en su artículo 7:

Será competente el juez o tribunal ante el que se tramite o se haya tramitado el proceso de responsabilidad patrimonial contra el Estado de acuerdo con las reglas de competencia señaladas en el Código Contencioso Administrativo.

Cuando la reparación patrimonial a cargo del Estado se haya originado en una conciliación o cualquier otra forma permitida por la ley para solucionar un conflicto con el Estado, será competente el juez o tribunal que haya aprobado el acuerdo o que ejerza jurisdicción territorial en el lugar en que se haya resuelto el conflicto. ${ }^{15}$

4. Oportunidad para presentar la demanda: sabiendo lo que la acción de repetición significa, lo que se pretende con ella y el órgano ante el que se debe presentar, es preciso entonces saber el tiempo que se tiene para incoarla. La respuesta a esto la da el literal i del artículo 164 de la Ley 1437 de 2011 en el siguiente tenor:

Cuando se pretenda repetir para recuperar lo pagado como consecuencia de una condena, conciliación u otra forma de terminación de un conflicto, el

14 Congreso de la República. Ley 1437 de 2011. Por la cual se expide el Código de Procedimento Admistrativo y de lo Contencioso Administrativo. Enero 18 de 2011.

15 Congreso de la República. Ley 678 de 2000 . Por medio de la cual se reglamenta la determinación de responsabilidad patrimonial de los agentes del Estado a través del ejercicio de la acción de repetición o de llamamiento en garantía con fines de repetición. Agosto 3 de 2001. 
término será de dos (2) años, contados a partir del día siguiente de la fecha del pago, o a más tardar desde el vencimiento del plazo con que cuenta la administración para el pago de condenas de conformidad con lo previsto en este Código. ${ }^{16}$

Término igual al consignado en la Ley 678 de 2001 artículo 11 y es igual al de la reparación directa de acuerdo a cuyo proceso también se tramitará la repetición según el artículo 10 de tal ley. ${ }^{17}$

\section{LA APLICACIÓN DEL MECANISMO DE REPETICIÓN POR PARTE DEL MINISTERIO PÚBLICO DELEGADO PARA EL CAQUETÁ Y LA ALCALDÍA DE FLORENCIA ENTRE EL AÑO 2010 AL 2016}

\section{Rama judicial}

Tribunal de lo Contencioso Administrativo del Caquetá:

Despacho Primero, Mag. Jesús Orlando Parra: informa que una vez revisado el sistema de siglo $\mathrm{XXI}$, se encontraron los siguientes procesos siendo demandante el Municipio de Florencia, a saber, Radicado: 2005-00234 y 2000-00010.

Despacho Segundo, Mag. Eduardo Javier Torralvo Negrete: no se encontraron procesos instaurados por el Municipio de Florencia o el Ministerio Público.

Despacho Tercero, Mag. Carmen Emilia Montiel Ortiz: no se encontraron procesos donde el medio de control sea el de repetición instaurados por el Municipio de Florencia.

Despacho Cuarto, Mag. Álvaro Javier González Bocanegra.

16 Congreso de la República. Ley 1437 de 2011. Por la cual se expide el Código de Procedimento Admistrativo y de lo Contencioso Administrativo. Enero 18 de 2011.

17 Congreso de la República. Ley 678 de 2000. Por medio de la cual se reglamenta la determinación de responsabilidad patrimonial de los agentes del Estado a través del ejercicio de la acción de repetición o de llamamiento en garantía con fines de repetición. Agosto 3 de 2001. 
Juzgados Administrativos del Caquetá:

Juzgado Primero Administrativo: no se conocieron acciones de repetición promovidas por el municipio o el Ministerio Público.

Juzgado Segundo Administrativo: no se dio respuesta a la petición pese a los múltiples requerimientos.

Juzgado Tercero Administrativo: se informa que se promovió ante el despacho un medio de control, donde el municipio es demandante.

Juzgado Cuarto Administrativo: manifiesta que para el periodo 2010-2016 no se ha presentado demanda alguna donde el demandante sea el Municipio de Florencia, Caquetá.

\section{Alcaldía Municipal}

La Alcaldía Municipal, por intermedio de la Oficina de Asesoría Jurídica, en contestación al derecho de petición, de fecha 18 de septiembre de 2017, informa que en el periodo 2010-2016 el ente territorial es parte procesal de 354 procesos litigiosos, y que se han incoado tres acciones de repetición, de las cuales una fue archivada y dos se encuentran en trámite.

Frente al número y monto de las condenas, se tienen los siguientes datos por vigencia:

\begin{tabular}{ccr}
\hline Vigencia & Condenas & Monto \\
\hline 2010 & 11 & $\$ 130879791$ \\
\hline 2011 & 11 & $\$ 880646523$ \\
\hline 2012 & 17 & $\$ 1163607538$ \\
\hline 2013 & 24 & $\$ 1689820148$ \\
\hline 2014 & 13 & $\$ 2771346054$ \\
\hline 2015 & 10 & $\$ 828626099$ \\
\hline 2016 & 3 & $\$ 86194673$ \\
\hline Total egresos en las vigencias 2010-2016 & & $\$ 7551120826$ \\
\hline
\end{tabular}

\section{Procuraduría General de la Nación}

De acuerdo con la contestación al derecho de petición, fechada el 30 de agosto de 2017, la Procuraduría Regional no ha adelantado procesos de repetición durante el periodo objeto del estudio. 


\section{LAS CIRCUNSTANCIAS QUE IMPIDEN LA EFICACIA DEL MEDIO DE CONTROL DE REPETICIÓN}

1. De lo desarrollado en el presente trabajo, corroborado con los escritos de los doctrinantes ya enunciados en acápites anteriores, se logró concluir que una de las circunstancias que dificultan el uso de la acción de repetición tiene que ver con el hecho de que sea la misma entidad condenada la encargada de estudiar la procedencia o no de la misma acción. Esto por cuanto pueden darse situaciones de carácter subjetivo que terminan siendo cortapisa a la hora de tomar la decisión de adelantar la acción, como por ejemplo no adelantarla por temor a generar represalias, por lo que distintos autores consideran como óbice el hecho de que estos comités de conciliación pertenecientes a la misma entidad condenada sean los encargados de dar viabilidad a la acción al no contar estos con la suficiente parcialidad a la hora de tomar la decisión de demandar por acción de repetición.

2. El hecho de que sea una acción civil y no una acción pública, impidiendo que cualquier persona pueda accionar, pues únicamente están facultados para ello la entidad de derecho público directamente perjudicada con el pago de la suma de dinero producto de una condena, conciliación u otra forma de conflicto, además del Ministerio Público y el Ministerio de Justicia y del Derecho.

3. Una de las causas sustanciales que afectan en gran medida la eficacia de la acción de repetición tiene que ver con el aspecto probatorio, existiendo una gran dificultad a la hora de dar viabilidad por parte del Comité de Conciliación, pues demostrar el dolo y la culpa en el actuar del funcionario dificulta esta tarea, aun más cuando en la mayoría de las sentencias en las que se condena a la entidad no se califica la actuación del funcionario, sino que únicamente se enjuicia la actuación de la administración.

\section{El impacto de las condenas y de las acciones de repetición}

El principal impacto que se deriva de la ineficacia del mecanismo jurisdiccional de la repetición es el impacto fiscal. Se tiene que en las vigencias de los años 2010 al 2016 hubo un egreso por concepto de condenas contra el Municipio de Florencia de 
un total de \$ 7551120826 (SIETE MIL QUINIENTOS CINCUENTA Y UN MILLONES, CIENTO VEINTE MIL OCHOCIENTOS VEINTISEIS PESOS), cifra que en la contabilidad del municipio no tiene retorno; es decir que el egreso registrado en estas vigencias como producto de la condena administrativa al municipio constituye una salida de dineros del arca pública que no retornan, pues la ineficacia del mecanismo de repetición impide que estos recursos retornen al municipio.

El capital que egresó por concepto de condenas contra el municipio es de un equivalente al 3,9\% del presupuesto para el año $2016^{18}$, con una representación asimilable en el gasto a la adición presupuestal19 para la financiación de:

\begin{tabular}{lr}
\hline Sistema de información & $\$ 382450526$ \\
\hline Programa de Alimentación Escolar & $\$ 72599095$ \\
\hline Calidad y gratuidad & $\$ 21757579$ \\
\hline Afiliación al régimen subsidiado continuado & $\$ 2094716865$ \\
\hline Salud pública & $\$ 107983640$ \\
\hline Deporte y recreación & $\$ 47616588$ \\
\hline Cultura & $\$ 35712497$ \\
\hline Otros & $\$ 452357571$ \\
\hline Atención, ampliación y continuación de la cobertura régimen subsidiado & $\$ 2980544129$ \\
\hline Coljuegos & $\$ 166511978$ \\
\hline Cuentas cedidas, atención y ampliación de cobertura régimen subsidiado & $\$ 32613363$ \\
\hline Total & $\$ 6394863771$ \\
\hline
\end{tabular}

Fuente: Acuerdo Municipal 012 de 2016

Frente al gasto público, se evidencia que el impacto es significativo; si bien es cierto que una representación porcentual del 3\% no es significativa, ante la comparación con la capacidad de inversión perdida en virtud de la ineficacia del mecanismo de repetición, se hace evidente el daño que se causa a la comunidad florenciana, quienes dejan de gozar de beneficios como mayor inversión en deporte, cultura, en ampliación del régimen subsidiado, etc. Inevitablemente, debe llegarse a la conclusión de que "la figura jurídica de la reparación directa no ha tenido el impacto socio-jurídico que el Constituyente quiso imponer"20.

18 Concejo Municipal de Florencia-Caquetá. Acuerdo 014. Por el cual se aprueba el presupueso de rentas y gastos para la vigencia del año 2016. Noviembre 25 de 2015.

19 Concejo Municipal de Florencia-Caquetá. Acuerdo Municipal 012. Por medio del cual se hace una adición al presupuesto de rentas y gastos para la vigencia del año 2016. Junio 21 de 2016.

20 Véase Maury Almanza Iglesias, Lauraine L. Ramírez y Ana Alfaro Martínez. Impacto de la aplicación de la acción de reparación directa y la inoperancia de la acción de repetición en el patrimonio económico del Estado. TEJIDOS SOCIALES REVISTA VIRTUAL 1. 2016. Págs. 14-28. 


\section{CONCLUSIONES}

En el municipio de Florencia, Caquetá, la eficacia de la acción de repetición en las vigencias 2010-2016 es nula. La Alcaldía tan solo se ha iniciado tres acciones de las cuales una se archivó, frente a un total de 89 condenas en contra del municipio.

El Ministerio Público no actúa en cumplimento de la función de accionar en repetición en defensa del patrimonio del municipio, escudado en que la ley permite pero no impone la posibilidad de accionar en repetición por parte del ministerio.

La fuga de capitales sin retorno afecta la inversión pública. Un ejemplo claro es la comparación de inversión realizada con la adición presupuestal del año 2016, en la que se logró una gran inversión social con menos recursos de los que hoy se representan en egresos de capital sin retorno por la inejecución de la acción de repetición en el municipio.

\section{REFERENCIAS}

Alejandro Peláez. Evaluación empírica de LA TASACIÓN DE PERJUICIOS INMATERIALES En COLOMBiA. Universidad de los Andes. (2015).

Álvaro Bustamante Ledesma. LA RESPONSABILIDAD EXTRACONTRACTUAL DEL ESTADO. Leyer. (2003).

Andrés Orión Álvarez Pérez. ANÁLISIS DE LAS RECIENTES SENTENCIAS DE UNIFICACIÓN JURISPRUDENCIAL PARA LA REPARACIÓN DE LOS PERJUICIOS INMATERIALES EN CONSONANCIA CON LA EVOLUCIÓN JURISPRUDENCIAL. Instituto Colombiano de Responsabilidad Civil y del Estado. (2014).

Andrés Orión Álvarez Pérez y Pascual Martínez Rodríguez. Estado actual de la jurisprudencia en relación con los perjuicios inmateriales. REVISTA IARCE 20. 2013.

Andrés Ricardo Mancipe González. LOS PERJUICIOS INMATERIALES EN LA RESPONSABILIDAD EXTRACONTRACTUAL DEL ESTAdo En Colombia. Trabajo de grado. Universidad Javeriana. (2005).

Caso Loayza Tamayo vs Perú. Serie C. N. ${ }^{\circ} 42$ (Corte Interamericana de Derechos Humanos, 27 de noviembre de 1998).

Congreso de la República. Ley 80 de 1993. Por la cual se expide el Estatuto General de Contratación de la Administración Pública. Octubre 28 de 1993. 
Congreso de la República. Ley 678 de 2000. Por medio de la cual se reglamenta la determinación de responsabilidad patrimonial de los agentes del Estado a través del ejercicio de la acción de repetición o de llamamiento en garantía con fines de repetición. Agosto 3 de 2000.

Congreso de la República. Ley 1437 de 2011. Por la cual se expide el Código de Procedimiento Admistrativo y de lo Contencioso Administrativo. Enero 18 de 2011.

Consejo de Estado. Sala de lo Contencioso Administrativo. Sentencia 8163 de 1993. (CP Juan de Dios Montes Hernández; 13 de julio de 1993).

Consejo de Estado. Sala de lo Constencioso Administrativo. Sección Tercera. Sentencia 199900326. (cP Olga Mélida De la Hoz; agosto 28 de 2014).

Consejo de Estado. Sección Tercera. Expediente 5835. Septiembre 27 de 1990.

Consejo de Estado. Sección Tercera. Subsección B. Fallo 19836. Junio 30 de 2011.

Concejo Municipal de Florencia-Caquetá. Acuerdo 014. Por el cual se aprueba el presupuesto de rentas y gastos para la vigencia del año 2016. Noviembre 25 de 2015.

Concejo Municipal de Florencia-Caquetá. Acuerdo Municipal 012. Por medio del cual se hace una adición al presupuesto de rentas y gastos para la vigencia del año 2016. Junio 21 de 2016.

Daniel Castaño Parra. El daño al proyecto de vida como nueva dimensión del daño inmaterial o no patrimonial. Comentarios a la sentencia del Consejo de Estado del 8 de marzo de 2007. REVISTA DERECHO DEL ESTADO 22. Enero-junio de 2009.

Édgar Arturo León Benavides. Acción DE REPETICIÓN: LEY 678 DE 2001. Librería Profesional. (2003).

Ida María Mestre Ordóñez y María Catalina Garcés Restrepo. LA ACCIÓN DE REPETICIÓN Y EL LLAMAmiento EN GARANTía LEY 678 DE 2001. Editorial Universidad Javeriana. (2004).

Juan Carlos Esguerra Portocarrero. LA PROTECCIÓn CONSTITUCIONAL AL CIUDADANO. Legis. (2004).

Libardo Rodríguez. DeRECHO ADMINISTRATIVo. Temis. (2000).

Maury Almanza Iglesias, Lauraine L. Ramírez y Ana Alfaro Martínez. Impacto de la aplicación de la acción de reparación directa y la inoperancia de la acción de repetición en el patrimonio económico del Estado. Tejidos Sociales Revista VIRTUal 1. 2016. Págs. 14-28. 
Natalia Zapata Mejía. (2011). La lucha continúa: necesidad de ampliar las causales de despenalización del aborto cuando el embarazo represente un daño al proyecto de vida de la mujer o subsidiariamente indemnización para esta cuando se le daña su proyecto de vida al imponerle la maternidad. Estudios DE DERECHO 152. 2011. Págs. 256-278.

Olga Amparo Barrientos Yépez. Letras JURídicAs Volumen 5. Editorial eEPP . (2000).

Presidencia de la República de Colombia. CARTILLA INSTRUCTIVA DE ACCIÓN DE REPETICIÓN Y LLAMAmiento en garantía. Presidencia de la República. (2004).

Real Academia Española. DiccionARIO de LA LENGUA ESPAÑOLA. 23. edición. RAE. (2014).

Viviana Marcela Pedraza Serrano y Santiago Naranjo Gómez. LOS PERJUICIOS INMATERIALES EN LA RESPONSABILIDAD CONTRACTUAL PúBliCA EN COLOMBIA. Editorial Universidad Javeriana. (2014). 